\title{
Money and medicine: the inextricable link
}

\section{Commentary}

\section{Big pharma}

Apart from the words President Trump, few other utterances possess the ability to make every man, woman and child tremble with genuine fear. Similar to The Donald, the term Big Pharma has come to connote something dishonest, malevolent, and thoroughly distasteful. An enigmatic entity consisting of corporations, regulators, politicians, and a growing number of physicians, Big Pharma has a vice like grip on western culture, shadowing us all like an ominous cloud. From the world of academia to the world of politics, Big Pharma is a contentious, unavoidable topic of discussion. Sen. Bernie Sanders, Vermont's answer to Doc Brown, was one of the first mainstream politicians to single out Big Pharma for criticism. For well over a decade, in typical Sanders fashion, the 74 year-old has worked tirelessly to break down the barrier surrounding patent protection for new medication. The disheveled looking renegade has spoken at length about radically slashing prescription drug spending. Unsurprisingly, the bold proposal has angered drug company lobbyists and high ranking officials, some of whom had, and continue to have, intimate connections with the Bush and Obama administrations. Up until quite recently, Sanders' warnings of a prescription fuelled America went largely ignored. Some labelled him a sensationalist, some labelled him a demagogue, and some labelled him a Communist. It appears he was and is neither of the three. Sanders' predictions were in fact as accurate as they were prescient. In October of 2015, when asked to rank the most important issues of the 2016 presidential campaign, New Hampshire residents ranked drug abuse as the number one area that needed addressing. This, in their opinion, was a more pressing issue than job creation and economic growth. Politicians started voicing their concerns, with the prophetic Sanders labeling addiction "a disease, not a criminal activity." More recently, cast your minds back to Super Bowl 50. Amid ads plugging savory snacks and sumptuous sports cars came an ad that was strange and striking. No, not the ad for Mountain Dew's 'Puppy Monkey Baby.' This ad, even more unexpected than a puppy, monkey, baby freak show, addressed OIC, or Opioid Induced Constipation. Considering a prime time, 30 second ad during the Super Bowl costs somewhere around \$5 million, the condition must be very real and somewhat rampant. Why, so many asked, was such a random advertisement airing during one of the most widely viewed sporting events in world history? And the answer might have something to with the fact that many drug companies have an inalienable, financially lucrative interest in painkiller medication. Although the advertisement sought to address the issue of OIC, the far greater issue concerns opioid use and opioid addiction.

\section{What exactly are opioids?}

They are a class of drugs that include the illegal drug heroin and the legal prescription pain relievers oxycodone, hydrocodone, codeine, morphine and fentanyl. ${ }^{1}$ Up until the last decade of the 20th century, opiates were either prescribed for the treatment of short-term pain or for chronic pain caused by terminal illnesses. However, in the 1990s, a

\author{
Volume 6 Issue 2 - 2017
}

\author{
John Glynn \\ Webster university, Thailand
}

Correspondence: John Glynn, Webster University, Thailand, Tel 35387465687I,Email john.glynn.gev@gmail.com

Received: July 29, 2016 | Published: March 20, 2017

dangerous myth swept across the medical community. Many doctors, manipulated by Big Pharma propaganda masquerading as medical literature, believed these drugs to be neither destructive nor addictive. The prescription of opiates became much more frequent and the selfserving desires of drug companies were assuaged. Recent studies show that nearly 22million Americans, ages 12 and up, struggle with substance abuse, with 2million suffering from a disorder involving prescription pain relievers. ${ }^{2}$ On May 11th of this year, shortly after meeting with presumptive Republican presidential nominee Donald Trump, House Speaker Paul Ryan drew attention to the work he and his associates were doing to address the nation's drug and opioid addiction crisis: "Right now, more Americans die every year from drug overdoses than car accidents. We are acting on 18 bills to deal with this. I hope that each and every one of you will be back here when we sign this bill." Indeed, prescription drug overdoses are crippling middle class America, and opioid addiction has enabled this epidemic to gain traction. Paul Ryan made a valid point, and that's a statement you seldom hear a liberal make. In 2015, according to various road crash statistics, 32,675 people were killed in motor vehicle crashes, with prescription drug and heroin overdoses alone claiming more than 29,000 lives. ${ }^{3}$ Overdose death rates are four times higher now than they were ten years' ago, and with 260 million prescriptions written for opioids on a yearly basis, the gap is widening. ${ }^{4}$ And just to put that 260 million figure into perspective - The U.S. has a population of 319 million. The Centers for Disease Control and Prevention, a leading national public health institute of the United States, recently published its guidelines for the prescription of opioids for chronic pain. As the nation's health protection agency, CDC stated that opioids should only be used when the benefits for pain relief clearly outweigh the risks, with avoidance of concurrent opioid and benzodiazepine use if at all possible. The progressive move received widespread approval from academics, addiction treatment professionals, divisive politicians like Hilary Clinton and Jeb Bush, as well as President Obama. Everyone with a conscience, it seemed, was behind the CDC initiative, everyone except those who stood to make a financial loss. After all, advisory guidelines could hamper pharmaceutical company 
profits, and heavyweights like Purdue Pharma, Johnson \& Johnson, and Endo Pharmaceuticals rushed to combat the threat. They made weak claims that such actions would make it too difficult for patients to access necessary medication, and, unsurprisingly, the feigned cries of concern worked. To this day, their legal representatives have succeeded in keeping the CDC from implementing policies of a genuinely substantial nature.

After all, there's money in medicine, and no one understands money-driven medicine quite like Big Pharma.

Take the Sackler family, for example, the people behind Purdue Pharma. As one of the richest families in the U.S., the Sackler's reportedly made their billions - 14 to be precise - from providing doctors and hospitals with huge amounts of OxyContin, a synthetic analgesic drug that Peter Shumlin, Governor of Vermont, recently labelled "the match that ignited America's opiate and heroin crisis." (Vermont has one of the highest rates of opioid addiction in the country). It's no coincidence that rising death tolls come at a time when the pharmaceutical industry is aggressively encouraging medical practitioners to prescribe highly addictive opioids. Primarily used for pain relief, opioids are now being prescribed for all manner of complaints, from persistent coughing to diarrhea. Acting on opioid receptors, the potent drug produces morphine-like effects, making the painkiller incredibly addictive and highly dangerous. I had the opportunity to interview Alan Cassels, a University of Victoria researcher and the co-author of 'Selling Sickness: How the World's Biggest Pharmaceutical Companies are turning us All into Patients' (co-written with Ray Moynihan). For two decades, Cassels, a former naval officer and diver, has immersed himself in very different waters, namely the murky ponds of pharmaceutical policy research. Primarily focusing on three areas: prescription drug information, pharmaceutical industry persuasion tactics and medical media, the Canadian is one of Big Pharma's most vocal adversaries. When asked to describe Big Pharma's influence on the world of prescription medication, Alan had this to say: "I think that pharma's influence on the act of prescribing is persuasive, pernicious, and very unhealthy for society and the health of the population. This is based on 20 years of observations of the industry and its bamboozlement of doctors and especially specialists who pretend to practice evidence-based medicine without realizing the 'evidence' it is basing prescribing decisions on has been thoroughly corrupted by, altered and misshapen by the company's marketing products." Keen to discuss Big Pharma's underhanded tactics, Cassels continued, "The pharmaceutical industry funds the misleading and frequently deceitful courting of politicians and health policymakers, who end up making decisions that favor the industry's profit margins It also funds unscrupulous marketing campaigns to consumers by buying patient and disease advocacy organizations or infiltrating those who cannot be bought." Cassels concluded the interview with an ominous assertion, "What isn't transparent, and is the most egregious concern, is the permeation of almost every organ that has a hand in physician education and training, all under the banner of 'evidence-based' (medicine), blindly purveying and spreading the idea of a drug for every ill." Because Big Pharma thrives on the notion that a drug exists for every ill, Cassel's final point is especially striking. With drug prices in the U.S. rising by $10 \%$ on an annual basis, suppressing the seemingly irrepressible greed of drug companies appears to be an improbable and unenviable task. Today, with prescription drugs becoming more expensive and legally allocated for a prescribed duration, heroin, once an outlier drug, has become a popular choice for upper-middle class Americans. With its ability to tranquilize the body and suppress pain, heroin often evokes temporary states of euphoria. In stark contrast to stimulants like cocaine, heroin is a depressant and is favored by users looking to self-medicate. After the euphoric effects wear off, however, a user may start to experience severe withdrawal symptoms, and it's common for long-term users to lose their teeth, experience respiratory illnesses, as well as manic depressive states, a loss of appetite, and chronic insomnia. It's no secret that heroin has made the transition into middle class society. No longer just a big city drug, heroin use is rampant in the suburbs. The U.S. is a country that loves to self-medicate, and heroin offers a transient escape from varying levels of anxiety and despair. Many users are well educated twenty-something's. Scaremongering and lectures on the detrimental effects of heroin no longer work. Did they ever? The sooner people realize that substance abuse, like cancer and diabetes, is a disease that requires close attention, the better. Labeling users criminals and dishing out prison sentences is an archaic, all too primitive response. A change is needed, however, tangible results are impossible to achieve if the pharmaceutical industry continues to manipulate and influence the treatment programs of patients across the nation. Arnold S. Relman, MD, who served as editor of The New England Journal of Medicine from 1977 to 1990, was one of the first to speak about the dangers posed by the "medical-industrial complex," the network of corporations which supply health care services and products for a profit. Dr. Relman, just like the aforementioned Sanders, was chillingly accurate and largely ignored. Today, with medical ghost writing rampant in the world of academia, Relman's warnings seems more relevant than ever before. This dishonest practice often involves an anonymous author employed by the industry or its service agencies to produce seemingly independent manuscripts for peerreviewed journals and conference presentations. Corporate-funded medical ghost writing continues to capture public interest and continues to blur the lines between ethical and legal practices. Common logic tells us that reputable studies require a reputable author, and this is where things take an even more sinister turn. Physicians are approached and encouraged-often through financial incentives-to attach their names to manuscripts as though they had conducted actual research. As many of these published papers are inaccurate and misleading, there is a certain irony in a doctor lending his or her name to doctored information. Pro Publica, a non-profit newsroom that specializes in investigative journalism, famously ran a piece which disclosed payments from pharma companies to doctors and other health care providers. The report named and shamed more than 20 well established, U.S. based doctors. Generously compensated by various drugs manufacturers, each medical practitioner received more than $\$ 500,000$ for speeches and consulting. ${ }^{5}$ AstraZeneca, Johnson \& Johnson and Eli Lilly, to name just three juggernauts of the pharmaceutical industry, have had to pay out sizeable sums in federal settlements over allegations that they approached doctors to promote drugs for unsanctioned uses. The major issue here has little to do with the fact that the these physicians most probably violated both medical school policies and federal laws (The money they received was never reported to either their affiliated academic institutions or the IRS). No, it's more worrying that these professionals promoted the 'findings' at national medical conferences and/or departmental meetings. Seemingly undeterred by all of the negative publicity and bad press, the divide between medical practitioners and the pharmaceutical industry continues to erode, both domestically and globally. China, with a population of 1.357 billion people, is struggling to provide healthcare for its vast and rapidly ageing population, and this challenge has presented Big Pharma with a new and lucrative opportunity. Although China harbors ambitions of developing and promoting its own pharmaceutical sector, the Middle Kingdom has little option but 
to reluctantly accept significant contributions from overseas. The U.S., unlike China, presents one major challenge for pharmaceutical companies - patent cliffs, a term which refers to the phenomenon of patent expiration dates and an abrupt drop in sales that follows for a group of products capturing high percentage of a market. Eastern Asia, and especially China, on the other hand, is a relatively new market, thus presenting pharmaceutical companies with a relatively open field, and it's no secret that the communist nation's regulatory environment is - at best - questionable. Furthermore, the world's most populous nation offers a wealth of patients willing to participate in clinical trials.

\section{How to stop big pharma?}

Well, that's the multi-billion dollar question that offers little in the way of concrete solutions. Ever since the 1930's, when the Rockefellers privatized healthcare in the United States, a subculture of unethical behavior and profit driven medicine gradually became mainstream. Today, if you happen to study any list detailing the most powerful companies in the U.S, you will see a number of pharmaceutical corporations listed. Big Pharma's influence, from drug wholesalers and chain pharmacies to medical conferences and academic journals, is extremely powerful. The next president of the
U.S. will have a major part to play in the demise or further ascension of Big Pharma, and if that president happens to be an orange haired, mini fingered baboon, don't bet on a rapid demise any time soon.

\section{Acknowledgements}

None.

\section{Conflict of interest}

Author declares that there is no conflict of interest.

\section{References}

1. https://www.drugabuse.gov/drugs-abuse/opioids

2. http://www.samhsa.gov/data/sites/default/files/NSDUH-FRR1-2014/ NSDUH-FRR1-2014.pdf

3. http://www.cdc.gov/nchs/data/health_policy/AADR_drug_poisoning involving_OA_Heroin_US_2000-2014.pdf

4. http://www.cdc.gov/vitalsigns/opioid-prescribing/

5. http://www.theguardian.com/society/2003/dec/07/health. businessofresearch 